\title{
PENERAPAN KEPEMIMPINAN TRANSFORMASIONAL DALAM MENURUNKAN BURNOUT PERAWAT PELAKSANA
}

\author{
Nur Wahyu Puspitasari ${ }^{1}$, Madya Sulisno2 ${ }^{2}$ Luky Dwiantoro33, Tri Nur Kristina ${ }^{4}$,Tri Hartiti ${ }^{5}$ \\ ${ }^{1}$ Puskesmas Darul Azhar Jl. Batu Benawa Kec. Simpang Empat, Kab.Tanah Bumbu \\ 2,3Program Studi Magister Keperawatan Fakultas Kedokteran Universitas Diponegoro \\ ${ }^{4}$ Program Studi Kedokteran Fakultas Kedokteran Universitas Diponegoro Jl.Prof Dr. Soedarto S.H, Kec.Tembalang, \\ Semarang.(024)7460024 \\ ${ }^{5}$ Fakultas IImu Keperawatan dan Kesehatan Universitas Muhammadiyah SemarangJl. Kedungmundu, Kec.Tembalang, Semarang \\ Email : nurwahyup@gmail.com
}

\begin{abstract}
ABSTRAK
Penelitian di Indonesia dan di luar negeri menunjukkan semakin meningkatnya burnout pada perawat yang merupakan gejala kelelahan fisik, emosional dan mental serta munculnya perasaan rendah diri akibat stres yang berkepanjangan. Penelitian ini bertujuan untuk membuktikan bahwa penerapan kepemimpinan transformasional dapat menurunkan burnout perawat pelaksana. Metode yang digunakan dalam penelitian ini adalah quasi eksperiment yang dilakukan di dua rumah sakit pemerintah di Karesidenan Surakarta terhadap 25 perawat pelaksana yang telah mengalami burnout dan pada 2 kepala ruang pada masing-masing rumah sakit sebagai kelompok intervensi dan kontrol. Data dibandingkan dengan independent $t$ test dan paired $t$ tes. Kelompok intervensi menunjukkan rerata skor burnout perawat pelaksana sebelum intervensi adalah 71.96 dan setelah intervensi menurun menjadi 49.52 dengan nilai $p$ 0,00 sedangkan pada kelompok kontrol rerata skor burnout perawat pelaksana sebelum intervensi 63,7 dan setelah intervensi 63,8 dengan nilai $p 0,81$. Berdasarkan rumus Cohen, efektivitas penerapan kepemimpinan transformasional masuk dalam kategori tinggi $(1,8)$. Simpulan dari penelitian ini penerapan kepemimpinan transformasional kepala ruang terbukti efektif dalam menurunkan burnout perawat pelaksana.
\end{abstract}

Kata Kunci: burnout; kepemimpinan transformasional; perawat pelaksana

\begin{abstract}
Research in Indonesia and abroad shows increasing nurses' burnout, which is a symptom of physical, emotional and mental fatigue and low feelings due to prolonged stress.. This study aims is to prove that the application of transformational leadership can reduce burnout in staff nurses. The methode used in this research was quasi-experiment, which is conducted in two government hospitals in the Surakarta Regency involving 25 burnout nurses and 2 heads of the ward in each hospital as intervention and control group. Data were compared by independent $t$ test and paired test. The results of this study showed that the burnout mean score of the nurse before intervention in the intervention group was 71.96, and after intervention was 49.52, with $p$ - value 0.00 while in the control group was 63.7 and 63.8 respectively with $p$ value 0.81 . Based on Cohen formula, this study showed that effect size of the intervention can be categorized as high (1.8). The conclusions of this research was that application of transformational leadership by head nurses could reduce burnout of staff nurses.
\end{abstract}

Keywords: burnout; transformational leadership; staff nurses 


\section{LATAR BELAKANG}

Burnout merupakan gejala kelelahan fisik, emosional dan mental dengan perasaan rendahnya harga diri akibat stres yang berkepanjangan. Berbagai penelitian di Indonesia melaporkan tingginya burnout dikalangan perawat dengan prevalensi yang berkisar antara 38\% -75 \% (Aulia, 2018) ,(Awalia, 2013), (Prestiana \& Purbandini, 2012), (Asamani, Naab, Maria, \& Ofei, 2016). (Mariyanti \& Citrawati, 2011), (Ningrum, 2014), (Eliyana, 2016), (Wati, 2017). Penelitian di luar negeri juga menunjukkan tingkat burnout yang tinggi dengan prevalensi $22 \%-98 \%$ sejak tahun 2013 sampai 2017 (Dolan et al., 2015), (Vargas, Can, Can, \& De, 2015), (Frey, Robinson, Wong, \& Gott, 2018), (Font, Corti, \& Berger, 2015), (Britt, Koranne, \& Rockwood, 2017).

Penelitian di RSUP Sanglah Denpasar ruang Medical Surgical didapatkan hasil 100\% perawat sering mengalami keletihan secara fisik, 75\% menyatakan sering mengalami keletihan secara emosional, 50\% menyatakan sering mengalami gangguan pola tidur, gangguan pola makan dan sakit kepala serta 50\% menyatakan sesekali ingin beralih ke profesi selain perawat (Saputra, 2016) Wawancara dengan 5 perawat di salah satu rumah sakit pemerintah di karesidenan Surakarta menyatakan bahwa beban kerja cukup tinggi, pasien yang banyak dan rutinitas kerja seringkali membuat jenuh dan lelah. Perawat yang lain merasa bahwa dirinya kadang kurang semangat dalam bekerja, bekerja sebagai perawat itu berat dan membosankan. Terkadang kurangnya peran pimpinan dalam menghadapi permasalahan pasien membuat perawat semakin jenuh. Keluarga yang menunggu pasien juga mengatakan terkadang perawat memberikan jawaban yang kadang dirasakan kasar saat ditanya, serta lambat merespon keluhan pasien.

Beberapa penelitian menunjukkan bahwa burnout yang tinggi berdampak negatif, mulai dari peningkatan beban kerja, tingginya biaya pegawai karena turnover yang tinggi, kepuasan kerja perawat menurun hingga berdampak pada penurunan kualitas asuhan keperawatan (Workman, 2017), (Madathil, Heck, \& Schuldberg, 2014), (Dolan et al., 2015), (Britt et al., 2017), (Sari, 2015), (Vargas et al., 2015), (Ramdan \& Fadly, n.d.), (Bahar, 2008), (Garcı \& Rı, 2016).
Burnout dapat dipengaruhi oleh beban kerja yang berlebihan, kurangnya dukungan keluarga, buruknya lingkungan kerja, dan kurang baiknya kepemimpinan. (Maslach, Schaufeli, \& Leiter, 2001). (Kanste, 2008). Beban kerja yang tinggi tanpa disertai dengan kompetensi yang memadai juga dapat memicu burnout. Burnout lebih berisiko muncul jika gejala memburuk dalam lingkungan kerja (Luh, Dian, Sari, Studi, \& Keperawatan, 2013) dan faktor yang paling berpengaruh dalam pembentukan lingkungan kerja adalah gaya kepemimpinan yang digunakan oleh seorang pemimpin dalam berhubungan dengan stafnya (Gentene, 2013).

Upaya untuk meminimalkan burnout antara lain meningkatkan kecerdasan emosional, koping individu, spiritualitas, hubungan dengan rekan kerja, serta meningkatkan aspek kepemimpinan perawat (Maslach et al., 2001), (Patrick, Wagga, Wales, Lavery, \& Campus, 2007), (Scaufeli \& Janczur, 2004), (Gentene, 2013), (Hunsaker, 2013). Salah satu gaya kepemimpinan yang sesuai dalam menghadapi perubahan, meningkatkan pro aktif bawahan dan membuat bawahan lebih merasa dihargai dan lebih menyentuh faktor emosional adalah gaya kepemimpinan transformasional (Asamani et al., 2016). (Hartiti, 2013), (Afandi, 2013). Gaya kepemimpinan transformasional memberikan sentuhan emosional yang lebih baik untuk perawat dan hal ini akan mempengaruhi tingkat burnout perawat. Penelitian tahun 2008 di Finlandia, tahun 2014 di San Diego Kalifornia, di Amerika Serikat, di Montana, dan di Australia, tahun 2015 di Kalimantan Barat, serta tahun 2017 di Atlantik tengah menunjukkan bahwa kepemimpinan transformasional berhubungan negatif dengan burnout perawat (Workman, 2017), (Madathil et al., 2014), (Kanste, 2008), (Cheng, Bartram, Karimi, \& Leggat, 2016), (Green, Miller, \& A, 2017).

Kepemimpinan transformasional adalah kepemimpinan yang mempunyai kekuatan mempengaruhi bawahan dengan cara-cara tertentu. Pemimpin transformasional membuat bawahan merasa dipercaya, dihargai, loyal dan respek kepadanya. Bawahan akan termotivasi untuk melakukan lebih dari yang diharapkan. Pemimpin transformasional menggunakan karisma, pertimbangan individual, dan stimulasi intelektual 
untuk menghasilkan upaya yang lebih besar, efektivitas, dan kepuasan bagi bawahannya (Bass \& Riggio, 2006), (Ancok, 2012),(Bteman \& Snell, 2009). Berdasarkan hal tersebut penelitian ini bertujuan untuk membuktikan bahwa penerapan kepemimpinan transformasional dapat menurunkan burnout perawat pelaksana.

\section{METODE}

Metode penelitian yang digunakan dalam penelitian ini adalah Quasi eksperimen dengan pre \&post test control group design. Populasi dalam penelitian ini adalah seluruh perawat pelaksana yang mengalami burnout di dua rumah sakit pemerintah di karesidenan Surakarta. Sampel dalam penelitian berjumlah 25 perawat pelaksana pada tiap rumah sakit, yang mengalami burnout yang diukur sebelumnya dengan pilot studi pada ruangan-ruangan yang perawatnya berisiko mengalami burnout. Berdasarkan hasil pilot studi tersebut, sampel diambil dari ruang bedah dan penyakit dalam.

Kuisioner baku Tranformational Leadership Quetionnare (TLQ) (Bass \& Riggio, 2006), (Doody \& Doody, 2012) yang dimodifikasi menjadi lembar observasi dan telah divalidasi oleh pakar kepemimpinan transformasional, digunakan untuk mengobservasi kinerja kepala ruang. Pelatihan dilakukan selama 1 hari, dilanjutkan dengan pendampingan selama 1 minggu kemudian penerapan secara mandiri oleh kepala ruang selama 1 bulan. Observasi penerapan kepemimpinan transformasional dilakukan sebelum pelatihan, 1 minggu setelah pelatihan dengan pendampingan, dan 1 bulan setelah pelatihan.

Burnout perawat pelaksana pada kelompok intervensi dan kontrol diukur sebelum dan sesudah intervensi menggunakan kuisioner Maslach Burnout Inventory (MBI) (Maslach et al., 2001), (Patrick et al., 2007). Uji beda dilakukan menggunakan paired $t$ test dan independent $t$ tes.

\section{HASIL}

\section{Karakteristik Responden}

Tabel 1. Menunjukkan bahwa tidak ada perbedaan signifikan pada karakteristik responden dari kelompok intervensi dan kontrol, kecuali status kepegawaian dimana kelompok intervensi lebih banyak PNS secara bermakna dibanding kelompok kontrol $(p=0,003)$.

Tabel 1. Karakteristik Responden pada Kelompok Intervensi dan Kontrol

\begin{tabular}{|c|c|c|c|c|c|c|c|}
\hline \multirow[t]{3}{*}{ No } & \multirow[t]{3}{*}{ Variabel } & & \multicolumn{4}{|c|}{ Kelompok } & \multirow[b]{3}{*}{$p$} \\
\hline & & & \multicolumn{2}{|c|}{$\begin{array}{c}\text { Intervensi } \\
(\mathrm{N}=25)\end{array}$} & \multicolumn{2}{|c|}{$\begin{array}{l}\text { Kontrol } \\
(\mathrm{N}=25)\end{array}$} & \\
\hline & & & Jumlah & $\%$ & Jumlah & $\%$ & \\
\hline \multirow[t]{3}{*}{1} & \multirow[t]{3}{*}{ Usia } & 20-30 tahun & 9 & 36 & 20 & 80 & \multirow{3}{*}{0,375} \\
\hline & & 31-40 tahun & 9 & 36 & 3 & 12 & \\
\hline & & $>40$ tahun & 7 & 28 & 2 & 8 & \\
\hline \multirow[t]{2}{*}{2} & \multirow[t]{2}{*}{ Jenis Kelamin } & Laki-laki & 8 & 32 & 10 & 40 & \multirow[t]{2}{*}{0,484} \\
\hline & & Perempuan & 17 & 68 & 15 & 60 & \\
\hline \multirow[t]{3}{*}{3} & \multirow[t]{3}{*}{ Pendidikan } & D3 & 17 & 68 & 19 & 76 & \multirow{3}{*}{0,917} \\
\hline & & S1 & 2 & 8 & 3 & 12 & \\
\hline & & Ners & 6 & 24 & 3 & 12 & \\
\hline \multirow[t]{2}{*}{4} & \multirow{2}{*}{$\begin{array}{l}\text { Status } \\
\text { Pernikahan }\end{array}$} & Belum Menikah & 6 & 24 & 6 & 24 & \multirow[t]{2}{*}{0,114} \\
\hline & & Menikah & 19 & 76 & 19 & 76 & \\
\hline \multirow[t]{3}{*}{5} & \multirow[t]{3}{*}{ Masa Kerja } & $<3$ Tahun & 7 & 28 & 7 & 28 & \multirow{3}{*}{0,427} \\
\hline & & 3-10 tahun & 9 & 36 & 13 & 52 & \\
\hline & & $>10$ tahun & 9 & 36 & 5 & 20 & \\
\hline \multirow[t]{2}{*}{6} & \multirow{2}{*}{$\begin{array}{l}\text { Status } \\
\text { Kepegawaian }\end{array}$} & PNS & 14 & 56 & 10 & 40 & \multirow[t]{2}{*}{$0,03^{*}$} \\
\hline & & Non PNS & 11 & 44 & 15 & 60 & \\
\hline
\end{tabular}




\section{Kepemimpinan Transformasional Kepala Ruang pada Kelompok Intervensi dan Kelompok Kontrol}

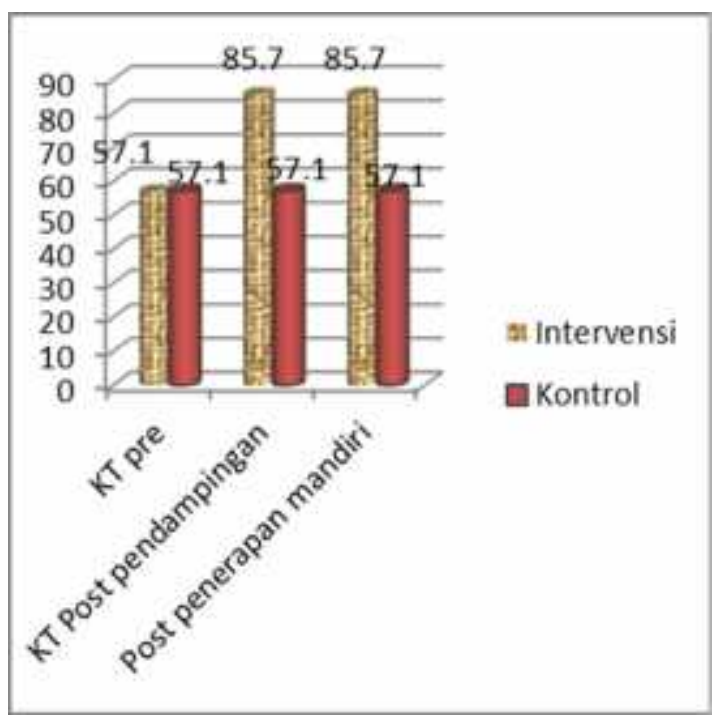

Gambar 1 menunjukkan bahwa dalam 3X observasi terdapat peningkatan penerapan kepemimpinan transformasional kepala ruang pada kelompok intervensi, sedangkan pada kelompok kontrol tidak ada perbedaan yang bermakna.

\section{Burnout Perawat Pelaksana Sebelum dan Sesudah diterapkan Kepemimpinan Transformasional Kepala Ruang}

Tabel 2 menunjukkan bahwa sebelum intervensi, kelompok intervensi dan kontrol memiliki tingkat burnout yang hampir sama, yaitu sebagian besar masuk dalam kriteria sedang, (rerata skor 71,9 \pm 4.6 pada kelompok intervensi dan 63,7 \pm 7.1 pada kelompok kontrol). Setelah intervensi, sebagian besar kelompok intervensi memiliki tingkat burnout yang berubah menjadi rendah, sedangkan pada kelompok kontrol burnout tingkat sedang masih dialami oleh seluruh responden $(p$ $=0.00)$.

Tabel 2 Perbedaan Burnout Perawat Pelaksana pada Kelompok Intervensi dan Kontrol

\begin{tabular}{|c|c|c|c|c|c|c|c|c|c|}
\hline \multirow[t]{2}{*}{ Burnout } & \multicolumn{4}{|c|}{ Intervensi } & \multicolumn{4}{|c|}{ Kontrol } & \multirow[t]{2}{*}{ Nilai $p$} \\
\hline & Jumlah & Rerata & SD & Min-Max & Jumlah & Rerata & SD & Min-Max & \\
\hline \multicolumn{10}{|l|}{ Sebelum } \\
\hline Sedang & 25 & 71.9 & \pm 4.64 & $64-82$ & 24 & 63.7 & \pm 7.09 & $44-76$ & 0.863 \\
\hline Rendah & - & & & & 1 & & & & \\
\hline \multicolumn{10}{|l|}{ Sesudah } \\
\hline Sedang & 4 & 49.7 & \pm 5.00 & $49-52$ & 25 & 63.8 & \pm 6.65 & $47-76$ & $0.000 *$ \\
\hline Rendah & 21 & & & & - & & & & \\
\hline Nilai $p$ & & $0.000^{*}$ & & & & 0.810 & & & \\
\hline
\end{tabular}

Tabel 3 menunjukkan dimensi burnout, dimana pada kelompok kontrol tidak terlihat adanya perbedaan signifikan pada ketiga dimensi burnout baik sebelum maupun sesudah intervensi, sedangkan pada kelompok intervensi terlihat adanya perbedaan yang bermakna kearah perbaikan.
Perbandingan dimensi burnout antara kelompok intervensi dan kelompok kontrol sebelum intervensi tidak terlihat adanya perbedaan signifikan dan setelah intervensi terdapat perbedaan yang signifikan. 
Tabel 3 Perbedaan Skor Dimensi Burnout Perawat Pelaksana pada Kelompok Intervensi dan Kontrol

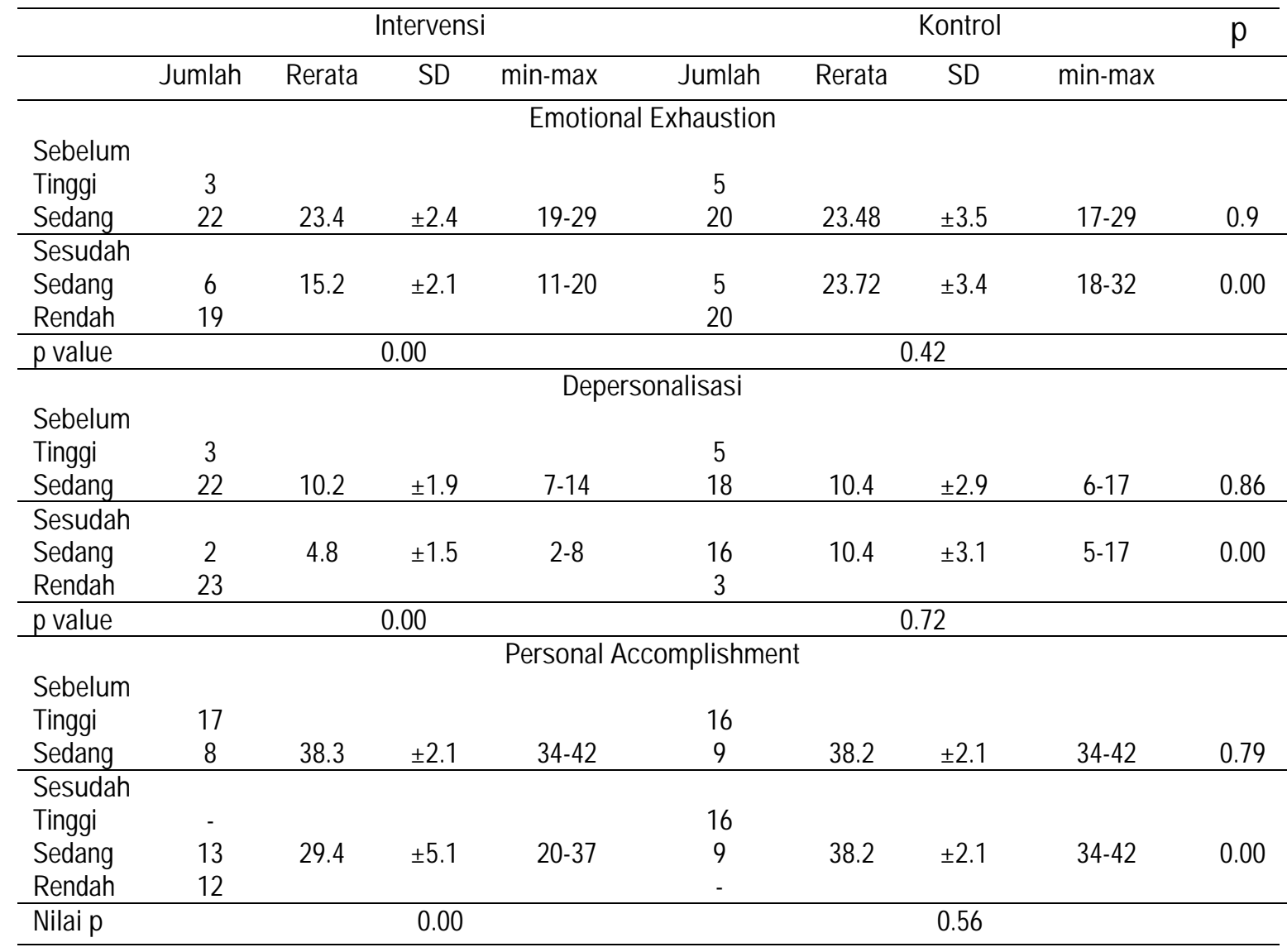

\section{PEMBAHASAN}

Hasil observasi kepemimpinan transformasional kepala ruang pada kelompok intervensi menunjukkan adanya peningkatan penerapan kepemimpinan transformasional. Sedangkan pada kelompok kontrol tidak terlihat adanya perbedaan yang signifikan pada penerapan kepemimpinan transformasional, baik pada observasi awal, kedua, maupun ketiga. Skor kepemimpinan transformasional pada kelompok intervensi meningkat dari 57,1 menjadi 85,7. Skor kepemimpinan transformasional pada kelompok kontrol tetap 57,1 hal ini menunjukkan bahwa kepala ruang pada rumah sakit kontrol memang belum memiliki kompetensi menerapkan kepemimpinan transformasional.

Hasil observasi pada kelompok intervensi juga menunjukkan perilaku kepemimpinan transformasional kepala ruang yang meningkat terutama perannya sebagai pembimbing (datang tepat waktu saat dinas, memunculkan ide kepada bawahan yang menghasilkan insentif dan membantu perawat saat mengatasi konflik).

Hasil penelitian menunjukkan bahwa sebelum intervensi, burnout perawat pelaksana pada kelompok intervensi sebagian besar masuk dalam kategori "sedang" pada dimensi emotional exhaustion dan depersonalisasi, serta masuk dalam kategori "tinggi" pada personal accomplishment. Ini memperlihatkan bahwa ratarata perawat mengalami burnout mulai tingkat sedang sampai tinggi yang terjadi di ruang bedah dan interna. Hasil penelitian ini sejalan dengan penelitian Rifqi tahun 2016 dan Teresa EvansTurner tahun 2014 (RH., 2012), (Teresa \& Turner, 2014). Burnout kategori tinggi pada dimensi personal accomplishment menunjukkan kurangnya penghargaan dari kepala ruang kepada perawat, sehingga membuat perawat merasa memiliki kemampuan kurang dan tidak percaya diri dalam dalam merawat pasien dan ini merupakan salah satu faktor yang cukup berperan dalam 
menyebabkan burnout, terutama ketika merawat pasien dengan beberapa permasalahan sekaligus.

Penurunan tingkat burnout pada dimensi emotional exhaustion pada penelitian ini cukup besar yaitu sebesar 8,26. Ini menunjukkan bahwa penerapan kepemimpinan transformasional terbukti dapat menurunkan burnout terutama pada dimensi emotional exhaustion. Hasil ini sejalan dengan penelitian Amy E. Green yang menunjukkan hubungan negatif antara emotional exhaustion dan depersonalisasi dengan kepemimpinan transformasional (Green et al., 2017), (Kanste, 2008), (Madathil et al., 2014). Penurunan ini dapat terjadi karena salah satu karakter kepemimpinan transformasional adalah mengartikulasikan visi masa depan dan membentuk ikatan emosional yang amat kuat dengan pengikutnya (L, Hughes, C, J, \& Curphy, 2012). Kepemimpinan transformasional juga lebih efektif menurunkan burnout perawat dibandingkan kepemimpinan transaksional (Workman, 2017). Perawat yang pada saat bekerja mendapatkan perlakuan baik dari pemimpinnya, meskipun beban kerja dan tuntutan kerja tinggi maka kemungkinan terjadinya burnout akan rendah karena saat dia bekerja, dia merasakan bahwa apa yang dilakukannya adalah sebuah prestasi, dan seseorang akan merasa senang jika memiliki prestasi, perasaan senang inilah yang mencegah terjadinya burnout (Sanches \& Souza, 2018).

Sebelum intervensi, burnout perawat pelaksana pada kelompok kontrol sebagian besar sudah masuk dalam kategori "sedang". Burnout tersebut juga menunjukkan kategori "sedang" pada dimensi emotional exhaustion dan depersonalisasi serta kategori "tinggi" pada personal accomplishment, dan tak berbeda bermakna pada pengukuran tahap kedua dan ketiga. Kelelahan emosional yang merupakan salah satu dimensi burnout mungkin dialami oleh kelompok kontrol tersebut sehingga bila diterapkan kepemimpinan transformasional mengkin akan sangat berperan dalam mengatasi burnout (Kanste, 2008), (Green et al., 2017), (Evans-turner, Gates, \& Higgins, 2010).

\section{KESIMPULAN}

Kepemimpinan transformasional terbukti dapat menurunkan burnout perawat pelaksana terutama pada dimensi emotional exhaustion.

\section{REFERENSI}

Afandi, R. (2013). Efektifitas Kepemimpinan Transformasional Pesantren Bagi Peningkatan Mutu Lembaga Pendidikan Islam, 1(1), 99-122.

Ancok, D. (2012). Psikologi Kepemimpinan dan Inovasi. (R. Rahmaat \& H. Retnowulan, Eds.). Erlangga.

Asamani, J. A., Naab, F., Maria, A., \& Ofei, A. (2016). Leadership styles in nursing management: implications for staff outcomes, 6(1), 23-36.

Aulia, I. (2018). Hubungan antara Hope dengan Burnout pada Perawat di Kota Makassar. Universitas Hasanuddin.

Awalia, N. (2013). Analisis Burnout Perawat di Ruang Rawat Inap dengan Kunjungan Intensif dan di Ruang Perawatan Interna Syekh Yusuf Kabupaten Gowa.

Bahar, inta N. (2008). Hubungan antara gaya kepemimpinan atasan otoriter dengan burnout.

Bass, B. M., \& Riggio, R. E. (2006). Transformational Leadership (second). London: Lawrence Erlbaum Associates.

Britt, H. R., Koranne, R., \& Rockwood, T. (2017). Statewide improvement approach to clinician burnout: Findings from the baseline year. Burnout Research, 7(September), 29-35. https://doi.org/10.1016/j.burn.2017.11.002

Bteman, T. S., \& Snell, S. A. (2009). Manajemen dan Kolaborasi dalam Dunia yang Kompetitif. (E. Sembodo, Ed.) (2nd ed.). Jakarta: Salemba Empat.

Cheng, C., Bartram, T., Karimi, L., \& Leggat, S. (2016). Transformational leadership and social identity as predictors of team climate , perceived quality of care, burnout and turnover intention among nurses, 2025(2012). https://doi.org/10.1108/PR-052015-0118

Dolan, E. D., Mohr, D., Lempa, M., Joos, S., Fihn, S. D., Nelson, K. M., \& Helfrich, C. D. (2015). Using a Single Item to Measure Burnout in Primary Care Staff: A Psychometric Evaluation. Journal of General Internal Medicine, 30(5), 582-587. https://doi.org/10.1007/s11606-014-3112-6

Doody, O., \& Doody, C. M. (2012). 
Transformational Leadership in nursing practice, 21(20).

Eliyana. (2016). Faktor - Faktor yang Berhubungan dengan Burnout Perawat Pelaksana di Ruang Rawat Inap RSJ Provinsi Kalimantan BaratTahun 2015. Jurnal ARSI, 2, 172-182.

Evans-turner, T., Gates, S., \& Higgins, N. (2010). The Maslach Burnout Inventory and its relationship with staff transition in and out of the intellectual disability workforce.

Font, A., Corti, V., \& Berger, R. (2015). Burnout in Healthcare Professionals in Oncology. Procedia Economics and Finance, 23(October 2014), 228-232. https://doi.org/10.1016/S22125671(15)00320-2

Frey, R., Robinson, J., Wong, C., \& Gott, M. (2018). Burnout, compassion fatigue and psychological capital: Findings from a survey of nurses delivering palliative care. Applied Nursing Research, 43(June), 1-9. https://doi.org/10.1016/j.apnr.2018.06.003

Garcı, M., \& Rı, M. I. (2016). International Journal of Nursing Studies Patient satisfaction, stress and burnout in nursing personnel in emergency departments: : A cross-sectional study, $\quad 59, \quad 60-67$. https://doi.org/10.1016/j.jijnurstu.2016.02.008

Gentene, L. (2013). A Phenomenological Study of Nurse Strategies to Address Nursing Burnout, (January).

Green, A. E., Miller, E. A., \& A, A. G. (2017). Transformational Leadership Moderates the Relationship between Emotional Exhaustin and Turnover Intention among Community Mental Health Providers. Community Mental Health, 131(November), 321-330. https://doi.org/10.1007/s10597-0119463-0

Hartiti, T. (2013). Peningkatan Softskill Perawat melalui Kepemimpinan Ransformasional Kepala Ruang pada RS Swasta di Semarang. Jurnal Manajemen Keperawatan -Persatuan Perawat Nasional Indonesia, 1(2), 115-123.

Hunsaker, S. K. (2013). Identifying Factors That Influence Compassion Satisfaction, Burnout, and Compassion Fatigue in Emergency Department.
Kanste, O. (2008). The association between leadership behaviour and burnout among nursing personnel in health care, 4-8.

L, R., Hughes, C, R., J, G., \& Curphy. (2012). Leadership: Memperkaya Pelajaran dari Pengalaman. Jakarta: Salemba Humanika.

Luh, N., Dian, P., Sari, Y., Studi, P., \& Keperawatan, S. (2013). Hubungan Beban Kerja terhadap Burnout Syndrom pada Perawat Pelaksana Ruang Intermediet RSUP Sanglah, 5, 87-92.

Madathil, R., Heck, N. C., \& Schuldberg, D. (2014). Archives of Psychiatric Nursing Burnout in Psychiatric Nursing: Examining the Interplay of Autonomy, Leadership Style , and Depressive Symptoms, 28, 160-166.

Mariyanti, S., \& Citrawati, An. (2011). Burnout Pada Perawat Yang Bertugas Di Ruang Rawat Inap Dan Rawat Jalan Rsab Harapan Kita. Jurnal Psikologi, 9(2), 48.

Maslach, C., Schaufeli, W. B., \& Leiter, M. P. (2001). Job Burnout (pp. 397-422). Utrecht University.

Ningrum, Y. P. (2014). Hubungan antara Berbagai Gaya Kepemimpinan dengan Kejenuhan Kerja Perawat di IRNA Airlangga,Diponegoro dan Imam Bonjol RSUD "Kanjuruhan" Kepanjen Kab Malang.

Patrick, K., Wagga, W., Wales, S., Lavery, J. F., \& Campus, W. (2007). Burnout in Nursing, 24(3), 43-48.

Prestiana, N. D. I., \& Purbandini, D. (2012). Hubungan Antara Efikasi Diri (self efficacy) dan Stress Kerja dengan Kerja (burnout) pada Perawat IGD dan ICU RSUD Kota Bekasi. Soul, 5, 14.

Ramdan, I. M., \& Fadly, O. N. (n.d.). Analisis Faktor yang Berhubungan dengan Burnout pada Perawat Kesehatan Jiwa, 4.

RH., S. (2012). Buku Ajar Manajemen Keperawatan. Jakarta: EGC.

Sanches, R. S., \& Souza, A. R. De. (2018). Factors related to the development of stress and burnout among nursing professionals who work in the care of people living with HIV $I$ aids Fatores relacionados ao desenvolvimento de estresse e burnout entre profissionais de enfermagem que atuam na assistê, $\quad 10(1), \quad$ 276-282. https://doi.org/10.9789/2175- 
5361.2018.v10i1.276-282

Saputra, R. T. (2016). Hubungan Beban Kerja dengan Mutu Pelayanan Keperawatan DI Rawat Inap RSUD Sultan Syarif Mohammad Al Kadrie Pontianak.

Sari, I. K. (2015). Faktor-Faktor yang berhubungan dengan burnout Perawat di RSUD Haji Makassar.

Scaufeli, W. B., \& Janczur, B. (2004). burnout among nurses. Dutch: Western Wahington University.

Teresa, E., \& Turner. (2014). The Maslach Burnout Inventory and its Relationship with Staff Transition In and Out of The Intellectual Disability Workforce. New York.
Vargas, C., Can, G. A., Can, G. R., \& De, E. I. (2015). Risk factors and prevalence of burnout syndrome in the nursing profession. International Journal of Nursing Studies, 52, 240-249.

https://doi.org/10.1016/j.ijnurstu.2014.07.001

Wati, N. M. N. (2017). Pengaruh Caring Leadership Kepala Ruang terhadap Burnout Perawat Pelaksana di RSUD Wangaya Denpasar. Universitas Diponegoro.

Workman, J. J. (2017). Effect of Leadership Style and Employee Demographics on Employee Disengagement and Employee Burnout in a Mid-Atlantic Organization, (December). 